\title{
A rising tide of access: what consequences for equitable learning in Ethiopia?
}

Primary school enrolment in Ethiopia has more than doubled over the past two decades. In spite of this impressive achievement, and as in many low and middle-income countries that have experienced rapid expansion, the Ethiopian education system is characterised by a 'learning crisis' in which many children are leaving school without basic numeracy and literacy skills. In this paper, we explore the relationship between low learning levels and the features of an education system characterised by a sudden increase in learners from disadvantaged backgrounds, including 'first generation learners', or students whose parents have never been to school. Using unique longitudinal school survey data, we examine whether first generation learner status represents an additional layer of disadvantage in the Ethiopian education system; the relationship between first generation learner status and learning outcomes; and the educational trajectories of first generational learners through primary school. Based on these findings, we consider the implications of a rising tide of access for Ethiopia as it seeks to provide equitable, quality education for all by 2030 .

Keywords: primary education; learning crisis; equity; first generation learners; Ethiopia

\section{System expansion and the 'learning crisis' in Ethiopia}

The conditions of the 'global learning crisis' are now well established; while access to education has expanded rapidly in low and middle-income countries over the past two decades, hundreds of millions of children are leaving school without basic skills such as numeracy and literacy (World Bank 2018; Barakat et al 2016; Rose 2015; UNESCO 2014). The features of this learning crisis are readily apparent in Ethiopia. According to official statistics, net primary enrolment rose from 44 per cent in 1999-2000 to 93 per cent in 2015-16 (Assefar et al 2017; Ministry of Education 2017). While this is undoubtedly an impressive achievement, there remain serious issues relating to learning, system efficiency and equity in the Ethiopian education system. These challenges have persisted in spite of a consistent focus on education quality in successive government policies and sector plans (Education and Training Policy, 1994; 
Education Sector Development Plans I - V, 2003 - 2020), and in a large-scale package of government-led, donor-funded reforms, the General Education Quality Improvement Package (GEQIP, 2008 - 2020). Priority areas of previous GEQIP phases have included curriculum reform, textbook provision, teacher development, and school improvement grants, while the most recent phase of the reforms (GEQIP-E) focuses specifically on equity issues. This includes a focus on the 'emerging regions', , as well as the educationrelated challenges facing girls, children with disabilities and children from pastoralist families (World Bank 2017). Despite high levels of political support and donor funding, it is not clear the GEQIP reforms have yet had the desired impact on system efficiency and education quality.

The global learning crisis is often framed as a failure of education systems (World Bank 2018; UNESCO 2014). While there are undoubtedly significant challenges facing low-resource education systems, to what extent can the learning crisis in countries such as Ethiopia be understood as a function of rapid system expansion? Access to primary education has more than doubled over the past 15 years, transforming the Ethiopian education system from a de facto 'elite' to mass system within a relatively short period of time. The school population has therefore changed dramatically to include a much higher proportion of students from relatively disadvantaged backgrounds - including children whose parents have never been to school, or 'first generation learners' (FGLs); while at the same time Ethiopia has seen notable improvements in economic conditions. Persistent low learning levels may therefore partly reflect this increase in the proportion of disadvantaged students in schools - and a period of adjustment as schools respond to this change - rather than necessarily

\footnotetext{
1 Somali, Afar, Gambella and Benishangul-Gumuz, which are less densely populated, more remote regions of Ethiopia with historically low access to education.
} 
stagnation or decline in the quality of education offered by the system. In short, increases in student numbers and numbers of disadvantaged students may act as a countervailing influence on outcomes, limiting the improvement that might be expected from economic development and educational reforms (see Rolleston 2016).

In this paper, we explore the extent to which we can understand low learning levels in Ethiopia in these terms, and specifically, the implications of a higher proportion of FGLs in the system. An interest in FGLs raises a series of further questions; for example, we consider whether the disadvantage affecting FGLs may be understood simply in terms of a greater concentration of disadvantage in particular areas, in terms of greater levels of poverty among the school population, or alternatively, whether FGL status may represent an additional layer of disadvantage in itself. This has important implications for the education system in Ethiopia, and for other low and middle-income countries that have experienced a period of rapid expansion. A higher proportion of FGLs may present additional challenges for education systems, such as low levels of 'school readiness', which in turn may require systems to adjust the minimum levels of readiness either explicitly or implicitly assumed at school level. Another challenge arises from lower levels of home support among FGLs, which may be linked not only to poverty, but specifically to adult illiteracy. While adult literacy rates in Ethiopia have been rising steadily in recent years, ever-enrolment in school may be considered a poor indicator of meaningful learning where literacy outcomes are concerned. For example, based on analysis of Demographic and Health Survey (DHS) data from Ethiopia, Pritchett \& Sandefur (2017) find that almost 60 per cent of women who have completed lower primary education (up to Grade 4) are unable to read a simple sentence in their chosen language. 
We analyse longitudinal school survey data from Young Lives, an international study of child poverty, to identify the relationship between FGL status and learning outcomes, taking account of whether FGLs are more disadvantaged in other respects than their peers. We consider this in light of diversity across the regions in Ethiopia included in the Young Lives study, which vary considerably in their socio-economic and other conditions. We address the following research questions in our analysis:

(1) How prevalent is first generation learner status in the Young Lives sites in Ethiopia?

(2) What are the characteristics of first-generation learners when compared to their peers in the Young Lives sites?

(3) What is the relationship between first generation learner status and learning outcomes over time in the Young Lives sites?

Following an overview of recent education trends in Ethiopia and the methods used in our analysis, we present descriptive and multivariate analysis on access and learning among FGLs using Young Lives longitudinal data. By way of conclusion, we consider the implications of this analysis for the current phase of GEQIP reforms, and the importance of addressing the particular challenges facing FGLs if this reform package is to achieve its desired aim of raising learning outcomes equitably.

\section{Trends in access, learning and first generation learners in Ethiopia}

\subsection{Challenges facing the Ethiopian education system}

In spite of impressive improvements in access to basic education in Ethiopia, challenges persist relating to quality, efficiency and equity. Results from Ethiopia's National Learning Assessment (NLA), which has been conducted every four years since 2000, 
suggest learning outcomes in Grades 4 and 8 may be stagnating or even declining (World Bank 2016). While analysis of students' proficiency levels from the 2015 NLA indicates a slight improvement in some subjects, ${ }^{2}$ the vast majority of students in Grade

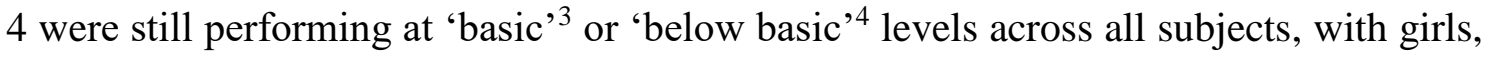
students in rural areas and students in government schools among the lowest performers (World Bank 2016). Analysis of Early Grade Reading Assessment (EGRA) data indicates that challenges of low learning start early in the system, and with wide variations across regions. In 2010, in the Sidama zone of the Southern Nations, Nationalities and Peoples' Region (SNNPR), 69 per cent of students were unable to read a single word, compared with only 10 per cent in Addis Ababa (Piper 2010).

In terms of system efficiency, primary completion and progression remain low compared to initial enrolment; according to official statistics, the completion rate at lower primary level (Grades 1-4) is 71 per cent, and only 54 per cent at upper primary level (Grades 5-8). The dropout rate has decreased in recent years (from 19 per cent in 2008-9 to 10 per cent in 2014-15), but grade repetition rates have remained somewhat constant over the same period (from 8 per cent in 2009 to 7 per cent in 2014) (Ministry of Education 2017). ${ }^{5}$ Meanwhile, despite overall progress in enrolment, a range of factors have been identified to constrain equitable educational opportunities in Ethiopia, including poverty (Rolleston 2016; Woldehanna \& Jones 2006), gender, rural locations

\footnotetext{
${ }^{2}$ It is important to note that different rounds of NLA are not strictly comparable over time, as different sampling strategies have been employed across rounds, and cognitive tests are not linked over time.

3 'Students at this level demonstrate a partial understanding of subject specific minimum learning competencies and have skills to solve some simple problems appropriate at the grade level' (World Bank 2016).

4 'Students at this level demonstrate a minimal understanding of subject-specific minimum learning competencies, and do not have skills to solve simple problems at grade level' (World Bank 2016).

${ }^{5}$ There is a policy of automatic promotion in the first four grades, after which repetition is permitted.
} 
(Woldehanna \& Gebremedhin 2012), pastoralist livelihoods (Woldab 2012), linguistic minority status (Tesfay \& Malmberg 2014), and disabilities (Beyene \& Tizazu 2012). According to 2016 DHS data, only around one quarter of the poorest 20 per cent complete primary school in Ethiopia ${ }^{6}$. Moreover, multiple factors of disadvantage are often found to compound one another (Rose et al 2016; UNESCO 2011). For example, low completion rates for the poorest are sometimes compounded by a child's area of residence and their gender; a poor girl living in the Afar region has only an 8 per cent chance of completing primary school, compared with 88 per cent for rich boys living in Addis Ababa ${ }^{7}$.

\subsection{First generation learners}

The positive effects of higher levels of parental education on children's educational outcomes - or the 'intergenerational transmission of human capital' - have been established by an extensive body of literature (e.g. Card et al 2018; Ermisch \& Pronzato 2010; Black et al 2005; Coleman 1966). We are, conversely, interested in the potentially adverse effects and equity implications of an absence of parental education. Many studies, particularly in the US, have examined the effects of first generation learner status for young people who are the first in their families to attend university (e.g. Ishitani 2006; Choy 2001; Billson \& Terry 1982). Exploring the implications of FGL status at earlier stages of education is of more relevance in low and middle-income countries; owing to the more recent expansion of basic education systems in these countries, we would expect more parents of school-going children to have had lower

\footnotetext{
6 Based on authors' calculations using DHS 2016 data. WIDE database, https://www.educationinequalities.org/.

7 Based on authors' calculations using DHS 2016 data. WIDE database, https://www.educationinequalities.org/.
} 
levels of access to schooling. However, to date, there has been limited analysis of the impact of FGL status beyond high-income countries. Among existing studies, Ghosh (2014) has explored the socio-cultural implications of being a first generation learner at primary school in India, including the tensions arising from 'existing on the margins of two cultures' at home and at school, while Jha \& Dhir (2002) have explored Indian teachers' sometimes negative attitudes towards first generational learners in their classrooms, due to the additional teaching challenges they present. Ogando \& Atherton (forthcoming) seek to expand the concept of FGLs to low and middle-income contexts, using longitudinal data from Ethiopia, India, Peru and Vietnam. In their analysis of Young Lives household data, Ogando \& Atherton find a much higher prevalence of FGLs (defined as neither parent has been to school) among primary school-age children in 2001-02 in Ethiopia (46 per cent) compared to other Young Lives countries (25 per cent in India, 5 per cent in Vietnam and 3 per cent in Peru).

These findings are perhaps unsurprising in light of the social, historical, political and economic context during which parents of current primary school-age children were eligible to attend primary school themselves. In the $1980 \mathrm{~s}-1990 \mathrm{~s}^{8}$, access to education was not only limited to a minority of the population, but was further affected by political and economic instability. In the 1980s, the socialist Derg regime prioritised the role of education for development and the 'inculcation of [Marxist] ideology' (Negash 2006), and the gross enrolment rate at primary level rose from 34 per cent in 1980 to 41 per cent in $1990^{9}$. However, perhaps foreshadowing the current learning crisis, according to Clapham (1990) 'a fairly good education for a relatively small number of

\footnotetext{
${ }^{8}$ Based on an average age of first childbirth in Ethiopia at 18-19 years (Gurmu \& Etana 2014).

9 Based on authors' calculations using World Bank Education Statistics, https://databank.worldbank.org/data/reports. aspx?source=education-statistics.
} 
children [under the previous Imperial education system] had under the socialist regime been transformed into quite a poor education for a much larger number of children' (quoted in Negash 2006: 20). Following an extended period of conflict and instability, the Derg regime was eventually overthrown by the current Ethiopian People's Revolutionary Democratic Front (EPRDF) government in 1991. As the country recovered from political turmoil, the gross enrolment rate at primary level dropped to 22 per cent in $1993^{10}$, before steadily rising over the 1990 s to reach 44 per cent in 1999 (Ministry of Education 2017). Over this period, there were considerable gender and wealth inequalities in educational access, while the availability of systematic information on learning outcomes was extremely limited (Colclough et al 2000). Following an overview of the data and methods used in our analysis, we examine how low levels of educational access among this generation has affected access and learning among current primary school-age children.

\section{Data and methods}

\subsection{Young Lives School Surveys}

Young Lives is a longitudinal study of childhood poverty in Ethiopia, India, Peru, and Vietnam. It has followed a total of 12,000 children divided into two age cohorts over the course of 15 years since its inception in 2001; an 'Older Cohort' born in 1994-95, and a 'Younger Cohort' born in 2001-02. In all four countries, a sentinel-site sampling $\operatorname{design}^{11}$ is employed, comprising twenty purposively selected sites chosen to represent

\footnotetext{
10 Based on authors' calculations using World Bank Education Statistics, https://databank.worldbank.org/data/reports. aspx?source=education-statistics.

11 The design is based on a 'sentinel site surveillance' approach most often used in health studies. This approach selects sites purposively to represent diversity with respect to key economic and demographic
} 
national diversity, but with an intended pro-poor bias. At the site level, children in both birth cohorts were selected randomly in 2001 , so that the data are representative of the birth cohort in each site (Outes-Leon and Sanchez 2008). In addition to five rounds of household surveys (conducted every 3-4 years from 2002 - 2016), school surveys were introduced in 2010 to permit further exploration of the educational experiences of Young Lives children and their peers.

The core 20 Young Lives sites are located in five of nine regions of Ethiopia: Addis Ababa, Amhara, Oromia, Southern Nations, Nationalities and Peoples' Region (SNNP) and Tigray. These regions are home to $96 \%$ of the population of children in Ethiopia, while the Young Lives sample is considered representative of $75 \%$ of the Ethiopian population overall (see Outes-Leon and Sanchez 2008 for details). Between three and five kebele ${ }^{12}$ were selected to form sites in each region in 2001. An additional 10 sites in two 'emerging' regions (Somali and Afar) were included for school surveys in 2012-13 and 2016-17. Owing to historically poor access to and use of services, these emerging regions were of particular interest to government and education stakeholders, hence their addition to the sample (Rossiter et al 2017).

The 2012-13 school survey was conducted in Ethiopia at lower primary level, with 13,724 Grade 4 and 5 students attending a total of 94 schools in seven regions. The 2016-17 school survey was conducted at upper primary level, with 13,943 Grade 7 and 8 students attending 63 schools in the same regions. A more detailed discussion of the sampling and survey design of the lower and upper primary school surveys in Ethiopia can be found in Aurino et al (2014) and Rossiter et al (2017) respectively.

characteristics. Accordingly, while not being statistically representative at national or regional level, sites represent key factors likely to impact on the outcomes of interest.

${ }^{12}$ Kebeles are comparable to 'wards', the smallest unit of administrative government in Ethiopia 
The regions excluded from the Young Lives surveys - Benishangul-Gumuz, Dire Dawa, Gambela and Harari represent less than two percent of the country's population. Among these, only Benishangul-Gumuz, representing around one percent of the population, ranks among the regions with very high rates of adult illiteracy. Accordingly, while the Young Lives surveys are not nationally or regionally representative in statistical terms, they do include sites from all of the most populated regions of the country and from all regions with high illiteracy except one. However, despite the 'pro-poor' sampling design, comparisons between Young Lives data and nationally representative sources of data, specifically the Demographic and Health Surveys (DHS) in 2000 and the Welfare Monitoring Survey in 2000 show that the Young Lives sample is slightly wealthier and has better access to services (see OutesLeon and Sanchez 2008). In terms of literacy, the Young Lives sample is also found to be more advantaged. For example, in the Young Lives household sample in 2002, 58\% of mothers reported no education, compared to $67 \%$ in DHS and 66\% in WMS. The equivalent figures for mother's illiteracy ${ }^{13}$ were $61 \%$ in Young Lives and $79 \%$ in DHS. There are a number of reasons why the Young Lives sample is more advantaged in some respects, including a greater proportion of urban dwellers than in a representative sample $^{14}$ (see Outes-Leon and Sanchez 2008).

\subsection{Methods}

In order to analyse the relationship between FGL status and learning outcomes, we first present descriptive analysis of the characteristics of FGL and non-FGL pupils, including geographical location. Among the results we include a number of indicators that are

\footnotetext{
${ }^{13}$ Defined as being unable to read any part of a single sentence presented in the household survey in the case of YL and DHS.

${ }^{14}$ This is partly due to issues of security in more remote parts of some regions.
} 
used subsequently in two simple modelling exercises. The full set of variables employed is enumerated in Appendices 1 and 2. While not statistically representative, the Young Lives data are employed to provide an illustration of the patterns of FGL in diverse contexts within Ethiopia.

As discussed in more depth in Ogando \& Atherton (forthcoming), FGL status can be defined in several ways, including in relation to (1) parental literacy or another measure of educational attainment; (2) the educational attainment level of one or both parents; (3) parental school enrolment or grade completion; and (4) the "educational distance' between students and their parents. The possible definitions of FGL status in our analysis are limited by the data available from the Young Lives 2016-17 school survey. Students were asked to record their mother and father's highest level of education according to eight categories ${ }^{15}$, and to record whether their mother and father could read and write in any language. This allows us to consider defining FGL status according to the first three definitions, but not according to the 'educational distance' between students and their parents, since data were not collected on the exact grade or educational level achieved by parents. After providing descriptive statistics according to these three possible definitions below, we employ the definition "neither parent has attended school' when examining FGL status. While this definition is more restrictive than a definition based on a single parent, it is less than a definition based on literacy given that, as discussed above, illiteracy is more widespread than never-attendance at school. Nonetheless, there may be some social benefits of attending school even if literacy skills are poorly developed which may affect attitudes to education (see Kaffenberger et al., forthcoming).

\footnotetext{
15 'Never been to school', 'up to Grade 4', 'up to Grade 8', 'up to Grade 10', 'TVET or Diploma', 'up to Grade 12', 'University', 'I don't know'.
} 
Using data from the Young Lives 2016-17 school survey, we start by presenting descriptive characteristics of FGLs, illustrating variation in the proportion of FGLs in Grades 7-8 and providing a comparison of key background characteristics between FGL and non-FGL students. Using regression analysis (employing a dichotomous outcome probability (probit) model), we then examine the factors at individual child and household levels that independently predict FGL status, conditioning on other relevant background factors. Subsequently, we use a simple linear regression model to consider whether FGL status disadvantages students in terms of learning outcomes in Grades 7-8 when controlling for other background characteristics, including a measure of earlier attainment (prior test score). Finally, we employ a sub-sample of 2,945 students who participated in both the 2012-13 and 2016-17 school surveys ${ }^{16}$ to examine the educational trajectories and learning gaps between FGL and non-FGL students over time.

\section{Increasing access, changing school populations}

\subsection{Defining first generation learner status}

We examine the prevalence of FGL status in the Young Lives 2016-17 school survey, according to the following definitions: 'neither parent can read or write' (definition 1); 'neither parent has been to school (definition 2) and a combination of these two definitions, 'neither parent has attended school and neither parent can read or write' (definition 3). Definition 3 is clearly the most restrictive, while the difference between definitions 1 and 2 indicates that a proportion of parents cannot read or write despite

\footnotetext{
${ }^{16}$ It is likely that the relatively low number of students found in both surveys is attributable to drop-out, repetition, migration and school choice. As a result, longitudinal analysis from the two school surveys should be interpreted with caution.
} 
prior school enrolment. In the Young Lives sample, using definition 1, 20.4\% of children are FGL, using definition 2, $11.9 \%$ and using definition 3, 8.0\%. For the reasons discussed above, these figures may be expected to be lower than nationally representative figures. Precise figures for the very specific age group represented by the Young Lives sample are not available but census data on literacy from Ethiopia provide a broad indicative picture. These are presented in Table 1. All regions show notable reductions in illiteracy between 1994 and 2007, while illiteracy remained very high in 2007 in the emerging regions of Afar and Somali.

[insert Table 1 here]

We adopt definition 2 (neither parent has been to school) in the analysis below, in light of our interest in understanding whether parental experiences of schooling (specifically, a lack thereof) influence their children's learning. Since Ethiopia is a context where there is a relatively high prevalence of FGLs, plus the likely compounding effect of having two parents who have received no schooling, we consider this relatively stringent definition to be more informative regarding the most marginalised children in Ethiopia.

\subsection{Are first generation learners more disadvantaged than their peers?}

There is a high level of regional variation in illiteracy in Ethiopia, as considered above. The proportions of FGLs in the Young Lives 2016-17 school survey sites also varies widely, as indicated in Figure 1. In Addis Ababa, Oromia and some SNNP sites, the proportion of FGLs is below 10 per cent; by contrast, in some sites in Somali and Afar, the proportion is 80 per cent or higher, broadly consistent with the national picture. There is also a high proportion of FGLs in disadvantaged sites in the SNNP, Amhara and Tigray regions. These site-level differences are more exaggerated than those found 
in current enrolment rates as, in effect, they reflect the education levels of the previous generation when access was concentrated in more advantaged locations. Sites that have seen the most rapid expansion in educational access, including the emerging regions of Somali and Afar, are therefore those with the highest proportion of FGLs and the highest rates of adult illiteracy.

[insert Figure 1 here]

We proceed to compare key background characteristics of FGL and non-FGL students in the 2016-17 school survey sample (Table 2). These characteristics include a 'wealth index' based on students' reports of household portable assets in the school survey $^{17}$; whether or not the student comes from an Amharic-speaking household ${ }^{18}$, and an indicator of child nutritional status in the form of a number of meals typically eaten each day $(1,2$ or $3+)$. Perhaps surprisingly, boys are more likely to be FGLs. In every other respect, FGLs are significantly more disadvantaged than their non-FGL peers ${ }^{19}$; they are older, live further away from school, come from poorer households, less likely to have attended pre-school, less likely to have used a computer outside school, and less likely to speak Amharic at home. The difference with respect to nutrition (average number of meals eaten per day) is somewhat smaller than for other indicators.

\footnotetext{
${ }^{17}$ Household wealth in the 2016-17 school survey was estimated using principal components analysis of data on assets and household consumer durables from each student. Consumer durables included in the Ethiopia wealth index include the following: table, chair, bed with mattress, radio, telephone, television, fridge, bicycle, car or truck.

${ }^{18}$ Historically, speaking Amharic has reflected higher access to education and higher socio-economic status in Ethiopia.

19 Based on t-tests for the difference in means within the YL sample as a whole. As the sample is comprised of purposively selected sites, results based on the aggregated sample should be considered indicative only.
} 
[insert Table 2 here]

Differences in background characteristics and learning outcomes represent forms of closely linked and mutually reinforcing disadvantage. In order to examine whether specific characteristics of FGLs differ significantly from those whose parents have at least some education, in the following section we therefore model the probability of FGL status based on a number of student background indicators. The indicators used for comparison are very simple, to allow meaningful comparisons given the diversity of contexts included in the sample. We employ a dichotomous outcome (probit) model where the outcome takes the value 1 for FGLs, and 0 for students with at least one parent who has some education. We report 'marginal effects' on the probability of being FGL for all predictor variables. We include site-level 'fixed effects', so that results compare children with their peers within each site. This approach therefore removes the effects of level-differences between sites in terms of educational access, which are substantial, in turn ensuring that FGLs and non-FGLs are not being compared across very heterogeneous contexts. As indicated in Figure 1, such leveldifferences at site level are very large; since these differences are based in historical reasons that are not the focus of the current exercise, we use fixed effects.

The results of this analysis (reported in Table 3 below) show that, with the exception of gender, there is a significant difference between FGLs and non-FGLs on all of the indicators. For example, students in poorer households (as indicated by wealth index) are more likely to be FGLs, even when controlling for their home language, age and nutritional status. Students from Amharic speaking homes are less likely to be FGLs compared to other students in the same sites, as are younger students (within the same grades) and those with better nutrition, in each case when controlling for the other predictors. Given the limited number of variables, we do not claim that these are 
specific effects - for example, FGL status may be predicted by nutritional status partly as a result of some other correlated form of disadvantage such as the type of crops farmed by a household engaged in agriculture.

[insert Table 3 here]

\subsection{What is the relationship between first generation learner status and learning outcomes?}

As demonstrated above, FGLs are significantly less advantaged than students who have at least one parent who has accessed some level of education. However, in order to understand the extent to which FGL status simply serves as a broad indicator of wider disadvantage, further analysis of the relationship between FGL status and learning outcomes is required.

Table 4 reports the average test scores in maths and English achieved by FGL and non-FGL students at the start of the school year in Grades 7 and 8. Both tests are scaled to have means of 500 and standard deviations of $100^{20}$. The gap in scores between FGLs and non-FGLs is 34 points (one third of standard deviation) in maths and 56 points (over half a standard deviation) in English. Both gaps are large, but the gap in English is especially notable. In Ethiopia, secondary schooling is conducted in English in all regions; low levels of English among FGLs are therefore likely to constitute a considerable barrier to meaningful access to the secondary school curriculum.

[insert Table 4 here]

\footnotetext{
${ }^{20}$ Raw scores on the maths test were transformed to a common scale, using a two-parameter item-response theory (IRT) model to produce estimates of children's latent ability or performance trait $(\Theta)$, which takes account of item difficulty and discrimination between students. See Rossiter et al (2017) and Iyer \& Moore (2017) for a more detailed discussion of the maths tests used in the Young Lives 2016-17 school survey in Ethiopia.
} 
Table 5 reports start-of-year maths results in more detail, showing results for the YL sites clustered in each region. This reveals that the gaps found in the aggregated data are somewhat driven by site-level differences in maths attainment between FGLs and non-FGLs. On average, FGL students in Addis Ababa sites outperform FGLs in all other regional site clusters. In some regional clusters - for example Amhara and Tigray - there is no significant gap in maths scores according to FGL status, while this gap is large and statistically significant in SNNP, Somali and Afar. Sites in these last two emerging regions have both a high proportion of FGLs and a large gap in attainment indicating that FGL status is an important marker of educational disadvantage in these contexts. In Oromia sites, there appears to be a 'reverse' attainment gap, in which FGLs outperform non-FGLs. However, it is important to note that there are very few FGL students $(\mathrm{n}=48)$ in the Oromia sample, so this reverse gap should be interpreted with caution.

[insert Table 5 here]

In light of these descriptive differences in learning outcomes according to FGL status, we proceed to further examine the relationship between FGL status and learning outcomes using a simple ordinary least squares (OLS) linear regression model. Firstly, we examine the effects of FGL status and other background characteristics on student maths test scores at the end of Grades 7 and 8 (column 1, Table 6). In a second model, we include students' maths test scores at the start of Grades 7 and 8 in order to examine the effects of the same characteristics on students' learning progress in maths (column 2, Table 6); that is, later learning outcomes conditioning on earlier outcomes, or a 'value-added' model. The benefit of a value-added approach is that the effects of other predictors may be interpreted as effects on the change in test scores between the two tests, as the first test score 'absorbs' the effects of influences exerted at both home and 
school up to the point the test was taken. Accordingly, we considerably reduce potential problems of correlation between the FGL indicator and advantages early on in a child's life that may lead to confounding - although we do not claim that the results may be interpreted in fully causal terms.

The results of these models indicate that, even when controlling for basic background characteristics, FGLs have lower end-of-year maths scores and, importantly, make less progress than their peers. These results suggest that FGLs not only under-perform when compared to other students by the end of Grades 7 and 8, but further that learning gaps between FGLs and their peers are widening over time.

[insert Table 6 here]

\subsection{What happens to first generation learners over the course of primary schooling?}

To explore trends over time among FGLs in more detail, we employ a sub-sample of 2,945 students who participated in both the Young Lives lower primary survey in 201213 and upper primary survey in 2016-17. This allows us to examine the educational trajectories of FGLs and their peers from Grade 4 (the end of the lower primary cycle) to Grade 8 (the end of the upper primary cycle), and the nature of any learning gaps that develop over this period between the two groups. Overall, 10.6 per cent $(n=312)$ of students in our linked sample are FGLs.

According to 'on time' grade progression, we would expect students enrolled in Grades 4 and 5 in 2012-13 to be enrolled in Grades 8 and 9 respectively in 2016-17 21 .

\footnotetext{
${ }^{21}$ Since Grade 8 is the final grade of compulsory education in Ethiopia and anticipating a considerable degree of grade repetition and over-age enrolment at upper primary level, the 2016-17 school survey was conducted in Grades 7 and 8.
} 
However, as shown in Table 7, we find that there are four cohorts within the linked sample:

- Cohort 1, who progressed on time from Grade 4 to 8 between the two surveys (65.6 per cent, $\mathrm{n}=1,933)$;

- Cohort 2, who progressed from Grade 4 to 7 between the two surveys, indicating repetition of one grade (13.3 per cent, $n=392)$;

- Cohort 3, who progressed from Grade 5 to 8 between the two surveys, again indicating repetition of one grade (15.8 per cent, $n=464)$; and

- Cohort 4, who progressed from Grade 5 to 7 between the two surveys, indicating repetition of two grades (5.3 per cent, $\mathrm{n}=156)$.

[insert Table 7 here]

Table 7 indicates considerable differences between these cohorts, as we might expect. Students who repeated a grade between surveys (Cohorts 2, 3 and 4) are more likely to be FGLs than those who progressed on time from Grade 4 to Grade 8 (Cohort 1), with the highest proportion of FGLs found in the cohort that repeated two grades between the surveys (Cohort 4). The expected age of students in Grades 4 and 5 are 10 and 11 years respectively; we find that students in all cohorts were older than the expected age for their grade in 2012-13, with students in Cohort 4 more than one year overage for Grade 5. Students who repeated grades between the surveys (Cohorts 2, 3 and 4) are also from less advantaged families than those who progressed on time (Cohort 1), based on a comparison of wealth index. 
To examine learning progress from lower to upper primary level for FGLs within our linked sample ${ }^{22}$, we focus on the 1,933 students in Cohort 1 - those who progressed on time between the two surveys. While this means we are focusing on a more advantaged group of students in our linked sample, a comparison of learning outcomes for this cohort is more robust given the larger sample size of both FGL and non-FGL students. Table 8 presents the data on the performance of FGLs and non-FGLs in Grades 4 and 8. FGLs not only under-perform in maths at the start of Grade 4 (33 points below their non-FGL peers), but make less-than-average progress over the year, meaning that the learning gap between FGL and non-FGL students widens by the end of Grade 4. Consistent with our preceding analysis in section 4.3, we also see a large gap between FGL and non-FGL students at the start of Grade 8 (44 points). While the difference in the mean progress made by FGLs and non-FGLs in Grades 4 and 8 is not statistically significant, the learning gaps between FGLs and their peers are significant at the end of both academic years. Based on average levels of progress during a school year, FGLs are in all cases more than one year 'behind' in terms of learning outcomes when compared to non-FGLs.

\section{[insert Table 8]}

Based on our descriptive analysis of this sub-sample of students, we find that FGLs who make the transition from lower to upper primary school are more likely to make 'inefficient' progress, repeating one or two grades over this period. Moreover, FGLs are out-performed by their peers who have at least one parent with some education at both stages of primary education, suggesting that schools are not yet

\footnotetext{
${ }^{22}$ It is important to note that maths performance in Grades 4 and 8 is not directly comparable across the two surveys, since maths tests were not linked on a common scale.
} 
providing FGL students with the additional support required to compensate for their disadvantage.

\section{Discussion}

The education system in Ethiopia has transformed from a somewhat 'elite' to a mass system in fewer than 15 years, and this rapid expansion of access to primary education is an impressive achievement in itself. However, a key question for Ethiopia and many other low and middle-income countries is how to provide quality education for all, especially for disadvantaged and marginalised students, in a system that has undergone such rapid transformation.

In this paper, we analysed unique longitudinal school survey data from Young Lives to examine the characteristics and learning outcomes of 'first generation learners' who have entered the school system in recent years, when compared to their peers who have at least one parent with some education. Our findings indicate that FGLs are considerably more disadvantaged than their peers in terms of their backgrounds, and that over the course of lower and upper primary schooling, gaps in learning outcomes widen between FGLs and their peers. These gaps widen even when conditioning on a number of background indicators that may be expected to capture key influences on learning progress. These findings suggest that the stagnation of learning outcomes in Ethiopia, quite apart from the quality of schooling provided, may also reflect an increase in the proportion of disadvantaged students in the education system during a period in which school enrolment increases have outpaced gains in adult literacy. The education system may have struggled to adapt to the needs of this changing school population, especially given its low levels of resources.

Since FGLs are likely to receive much lower levels of educational support at home, education systems such as Ethiopia's would, ideally provide higher levels of 
support to these students in schools with the aim of 'compensation' in the interests of equity. Adaptation, however, is also crucial for equitable provision. For example, 'teaching at the right level' could be an important step to counter lower levels of school readiness among FGLs, by ensuring that both the curriculum and pedagogy are flexible enough to adapt to lower learning levels and slower learning progress among FGLs. The recent expansion of pre-primary education in Ethiopia provides an opportunity to start such interventions early and to redress initial inequalities (Woodhead et al 2017; Rossiter et al 2018). Ensuring that the teaching and learning process is oriented so that all children reach age-appropriate 'minimum standards' (such as functional literacy or reading fluency), by the time they leave primary school is another way schools can ensure more equitable outcomes for FGLs as these students are likely to benefit more from the establishment of such benchmarks and associated strategies. Overall, if learning outcomes are to be raised equitably in Ethiopia, these are key areas that must be considered as part of reforms such as the General Education Quality Improvement Package for Equity (GEQIP-E, 2018 - 2022). Our findings suggest that FGL status is an additional, compounding factor of disadvantage both in terms of progression and learning outcomes at primary level; the Ethiopian education system must adapt to accommodate these students if a rising tide of opportunity is to be realised from education and learning for all.

\section{References}

Aurino, E., James, Z. \& Rolleston, C. (2014) Young Lives Ethiopia School Survey 201213: Data Overview Report. Young Lives Working Paper 134. Oxford: Young Lives.

Barakat, B., Bengtsson, S., Muttarak, R., Kebede, E. B., Cuaresma, J. C., Samir, K.C. \& Striessnig, E. (2016) Education and the Sustainable Development Goals. 
Background Paper prepared for the 2016 Global Education Monitoring Report. Paris: UNESCO.

Billson, J. M. \& Terry, M. B. (1982). 'In search of the silken purse: Factors in attrition among first-generation students', College and University, 58(1), 55 - 75.

Black, S. E., Devereux, P. J., Salvanes, K. G. (2005) 'Why the apple doesn't fall far: understanding intergenerational transmission of human capital', The American Economic Review 95 (1): 437 - 449.

Card, D., Domnisoru, C., Taylor, L. (2018) The intergenerational transmission of human capital: evidence from the golden age of upward mobility. Working Paper 25000. Cambridge, MA: National Bureau of Economic Research.

Central Statistical Agency \& ICF (2016) Ethiopia Demographic and Health Survey 2016. Addis Ababa and Rockville, MD: CSA and ICF.

Choy, S. (2001). Students whose parents did not go to college: Postsecondary access, persistence, and attainment. NCES Rep. No. 2001-126. Washington, DC: National Centre for Education Statistics.

Colclough, C., Rose, P. and Tembon, M. (2000). 'Gender inequalities in primary schooling: The roles of poverty and adverse cultural practice', International Journal of Educational Development. 20 (2): 5 - 27.

Coleman, J. S. (1966) Equality of educational opportunity. Washington, D.C.: National Centre for Education Statistics.

Ermisch, J. \& Pronzato, C. (2010) Causal effects of parents' education on children's education. ISER Working Paper Series No 2010-16. Colchester: Institute for Social and Economic Research.

Ghosh, S. (2014). 'The silent exclusion of first generation learners from educational scenario-a profile from Puncha block of Purulia district, West Bengal'. International Journal of Developmental Research 4 (3): 804 - 811.

Gurmu, E. \& Etana, D. (2014) 'Age at first marriage and first birth interval in Ethiopia: analysis of the roles of social and demographic factors'. African Population Studies 28 (3): 1332 - 1344.

Ishitani, T. T. (2006) 'Studying attrition and degree completion behaviour among firstgeneration college students in the United States', Journal of Higher Education $1(1), 1-12$. 
Iyer, P. \& Moore, R. (2017) 'Measuring learning quality in Ethiopia, India and

Vietnam: from primary to secondary school effectiveness', Compare: A Journal of Comparative and International Education 47 (6): 908 - 924.

Jha, J., \& Dhir, J. (2002). Elementary Education for the Poorest and other Deprived Groups. New Delhi: Centre for Policy Research.

Kaffenberger, M., Pritchett, L., \& Sandefur, J. (forthcoming). Estimating the Impact of Women's Education on Fertility, Child Mortality, and Empowerment When Schooling Ain’t Learning'. Oxford: RISE (Research on Improving Systems of Education) Working Paper

Ministry of Education (2015) Education Sector Development Programme (ESDP V), 2008-2012 E.C., 2015/16 - 2019/20 G.C.: Programme Action Plan. Addis Ababa: Federal Ministry of Education.

Ministry of Education (2017) Education Statistics Annual Abstract, 2008 E.C.

(2015/16). Addis Ababa: Federal Ministry of Education.

Negash, T. (2006) Education in Ethiopia: from crisis to the brink of collapse.

Discussion Paper 33. Uppsa;a: Nordiska Afrikainstitutet.

Orgando, M. and Atherton, P. (forthcoming) 'First generation learners: A binding constraint to learning. An explanatory study using young lives data' Review of Development Economics.

Outes-Leon, I. \& Sanchez, A. (2008) An Assessment of the Young Lives Sampling Approach in Ethiopia. Young Lives Technical Note 1. Oxford: Young Lives.

Piper, B. (2010) Ethiopia Early Grade Reading Assessment. Data Analysis Report: Language and Early Learning. Research Triangle Park, NC: RTI International.

Pritchett, L. \& Sandefur, J. (2017) 'Girls' schooling and women's literacy: schooling targets alone won't reach learning goals'. RISE Working Paper 17/011. Oxford: Blavatnik School of Government.

Rolleston, C. (2016). Escaping a Low-Level Equilibrium of Educational Quality. RISE Working Paper 16/008. Oxford: Blavatnik School of Government.

Rose, P. (2015) 'Three lessons for educational quality in post-2015 goals: Clarity, measurability and equity' International Journal of Educational Development. 40: $289-246$.

Rossiter, J., Azubuike, B. \& Rolleston, C. (2017) Young Lives School Survey, 2016-17: Evidence from Ethiopia. Oxford: Young Lives. 
Rossiter, J.; Hagos, B.; Rose, P.; Teferra, T.; \& Woldehanna, T. (2018) Early Learning in Ethiopia: Equitable access and Learning. System Diagnostic Report for World Bank Early Learning Program.

UNDP (2014) MDG Report 2014: Assessment of Ethiopia's Progress towards the MDGs. Addis Ababa: National Planning Commission and UN Ethiopia.

UNESCO (2014) Education for All Global Monitoring Report 2013-4: Teaching and Learning: Achieving Quality for All. Paris: UNESCO.

UNESCO (2019) 'Ethiopia - primary completion rate'. World Inequality Database on Education (WIDE), https://www.educationinequalities.org/countries/ethiopia/indicators/comp_prim_v2\#?dimension=all\& group $=$ all\&age_group $=\mid$ comp_prim_v2\&year $=\mid 2016$. Accessed 16 January 2019.

UNICEF (2015) Evaluation of Learning Achievement in Selected Woredas in Amhara and Addis Ababa Sub-Cities: Mid-Term Report. Addis Ababa: UNICEF.

World Bank (2013) Project Appraisal Document for a General Education Quality Improvement Project II. Report No. PAD476. Washington, D.C.: World Bank.

World Bank (2016) Striving for Excellence: Analysis of Ethiopia National Learning Assessments, 2011 and 2015. Washington, D.C.: World Bank.

World Bank (2017) Program-For-Results Information Document (PID): Concept Stage. Education for Growth and Transformation (GEQIP III). Report No. PIDC0110495. Washington, D.C.: World Bank.

Woodhead, M., Rossiter, J., Dawes, A. and Pankhurst, A. (2017). 'Scaling-up early learning as a sustainable development priority: A case study of Ethiopia'. In Miller, L., Cameron, C. Dalli, C. and Barbour, N. (eds.). Sage Handbook of Early Childhood Policy, pp. 219-235. New York: Sage.

World Bank (2017) Program Appraisal Document: General Education Quality Improvement Program for Equity (GEQIP E). Washington, D.C.: World Bank. 
Appendix 1. Summary statistics for variables used in analysis: probability of first generation learner status

\begin{tabular}{lllllll}
\hline VARIABLES & Description & Obs. & Mean & Std. Dev. & Min. & Max. \\
\hline age & Age (years) & 11,872 & 14.363 & 1.549 & 11 & 29 \\
gender & Male & 11,865 & 0.498 & 0.500 & 0 & 1 \\
sttmsch & $\begin{array}{l}\text { Distance to school } \\
\text { (minutes) }\end{array}$ & 11,866 & 24.856 & 20.754 & 1 & 180 \\
statdpre & Attended pre-school & 11,727 & 0.601 & 0.490 & 0 & 1 \\
wi_pca & Wealth index & 12,182 & $-1.84 \mathrm{e}-09$ & 1.802 & -4.034 & 2.817 \\
comp & $\begin{array}{l}\text { Uses a computer outside } \\
\text { school }\end{array}$ & 11,777 & 0.322 & 0.467 & 0 & 1 \\
lang2 & Speaks Amharic at home & 11,575 & 0.491 & 0.499 & 0 & 1 \\
stdmeal & Number of meals per day & 11,856 & 2.78 & 0.497 & 1 & 3 \\
\hline
\end{tabular}


Appendix 2. Summary statistics for variables used in analysis: first generation learner status, background characteristics and learning outcomes in Grades 7-8

\begin{tabular}{|c|c|c|c|c|c|c|}
\hline VARIABLES & Description & Obs. & Mean & Std. Dev. & Min. & Max. \\
\hline fgl & First generation learner & 10,881 & 0.133076 & 0.3396725 & 0 & 1 \\
\hline gender & Male & 11,865 & 0.498 & 0.500 & 0 & 1 \\
\hline age & Age (years) & 11,872 & 14.363 & 1.549 & 11 & 29 \\
\hline wi_pca & Wealth index & 12,182 & $-1.84 \mathrm{e}-09$ & 1.802 & -4.034 & 2.817 \\
\hline stdmeal & Number of meals per day & 11,856 & 2.78 & 0.497 & 1 & 3 \\
\hline sttmsch & $\begin{array}{l}\text { Distance to school } \\
\text { (minutes) }\end{array}$ & 11,866 & 24.856 & 20.754 & 1 & 180 \\
\hline stpplhm & Persons in family home & 11,887 & 6.59889 & 3.08745 & 1 & 28 \\
\hline statdpre & Attended pre-school & 11,727 & 0.601 & 0.490 & 0 & 1 \\
\hline
\end{tabular}


Table 1. Adult Illiteracy by Region in Ethiopia

\begin{tabular}{|l|l|l|}
\hline & $\mathbf{1 9 9 4}$ (age 5+) & $\mathbf{2 0 0 7}$ (age 5+) \\
\hline Tigray & 20.5 & 45.4 \\
\hline Afar & 7.3 & 17.3 \\
\hline Amhara & 17.8 & 38.0 \\
\hline Oromia & 22.4 & 46.8 \\
\hline Somali & 8.0 & 14.0 \\
\hline Benishangul-Gumuz & 17.7 & 39.5 \\
\hline SNNP & 24.4 & 41.8 \\
\hline Gambella & 29.3 & 49.5 \\
\hline Harari & 54.5 & 59.7 \\
\hline Addis Ababa & 82.5 & 85.3 \\
\hline Dire Dawa & 51.5 & 61.4 \\
\hline Total & $\mathbf{2 3 . 4}$ & $\mathbf{3 9 . 8}$ \\
\hline
\end{tabular}

Sources: Ethiopia CSA 1994, CSA 2007 
Table 2. Characteristics of first-generation learners in Grades 7 and 8.

\begin{tabular}{|c|c|c|c|c|c|c|c|c|}
\hline & $\begin{array}{l}\text { Age } \\
\text { (years) }\end{array}$ & $\begin{array}{c}\text { Female } \\
(\%)\end{array}$ & $\begin{array}{l}\text { Time to } \\
\text { school } \\
\text { (mins) }\end{array}$ & $\begin{array}{c}\text { Attended } \\
\text { pre-school } \\
(\%)\end{array}$ & $\begin{array}{c}\text { Wealth } \\
\text { index }\end{array}$ & $\begin{array}{c}\text { Used a } \\
\text { computer } \\
\text { outside } \\
\text { school } \\
(\%)\end{array}$ & $\begin{array}{c}\text { Speaks } \\
\text { Amharic } \\
\text { at home } \\
(\%)\end{array}$ & $\begin{array}{c}\text { Meals } \\
\text { per day } \\
\text { (meals) }\end{array}$ \\
\hline FGL & 14.8 & 44.8 & 31.1 & 36.0 & -1.4 & 12.8 & 30.0 & 2.7 \\
\hline $\begin{array}{l}\text { Not } \\
\text { FGL }\end{array}$ & 14.3 & 50.9 & 23.9 & 63.0 & 0.2 & 34.9 & 52.0 & 2.8 \\
\hline Sig. & $* * *$ & $* * *$ & $* * *$ & $* * *$ & $* * *$ & $* * *$ & $* * *$ & - \\
\hline
\end{tabular}

t-test significance: $* * * p<0.01, * * p<0.05, * p<0.1$. 
Table 3. Probability of first-generation learner status in Grades 7 and 8.

\section{VARIABLES}

Age

Gender (male)

Distance to school

Attended pre-school

Wealth index

Uses a computer outside school

Speaks Amharic at home

Number of meals per day
First generation learner status

$$
\begin{gathered}
0.0113 * * * \\
(0.00155) \\
0.00631 \\
(0.00490) \\
0.000330 * * * \\
(0.000107) \\
-0.0263 * * * \\
(0.00559) \\
-0.0228 * * * \\
(0.00172) \\
-0.0336 * * * \\
(0.00550) \\
-0.0540 * * * \\
(0.00883) \\
-0.0161 * * * \\
(0.00463)
\end{gathered}
$$

Observations

Site-level fixed effects

Yes 
Table 4. Start-of-year maths and English scores by first generation learner status, Grades 7 and 8 .

\begin{tabular}{lcc}
\hline & Maths score & English score \\
\hline FGL & 470 & 451 \\
Not FGL & 504 & 507 \\
Sig. & $* * *$ & $* * *$ \\
\hline \multicolumn{2}{c}{ t-test significance: $* * * \mathrm{p}<0.01, * * \mathrm{p}<0.05, * \mathrm{p}<0.1}$.
\end{tabular}


Table 5. Start-of-year maths scores by first generational learner status and region, Grades 7 and 8.

\begin{tabular}{lcccccccc}
\hline & Addis Ababa & Amhara & Oromia & SNNP & Tigray & Somali & Afar & Total \\
\hline FGL & 539 & 464 & 532 & 469 & 464 & 470 & 446 & 470 \\
Not FGL & 563 & 472 & 495 & 494 & 472 & 498 & 479 & 504 \\
Sig. & $*$ & - & $* *$ & $* *$ & - & $* * *$ & $* * *$ & $* * *$ \\
\hline
\end{tabular}

t-test significance: $* * * \mathrm{p}<0.01, * * \mathrm{p}<0.05, * \mathrm{p}<0.1$. 
Table 6. First generation learner status, background characteristics and learning outcomes in Grades 7-8.

\begin{tabular}{lcc}
\hline VARIABLES & $\begin{array}{c}(\mathbf{1}) \\
\text { End of year maths } \\
\text { score }\end{array}$ & $\begin{array}{c}(\mathbf{2}) \\
\text { Maths } \\
\text { progress }\end{array}$ \\
\hline \multirow{2}{*}{ First generation learner } & $-15.99 * * *$ & $-6.366^{* *}$ \\
Gender (male) & $(3.745)$ & $(2.749)$ \\
& $16.59 * * *$ & $5.108^{* * *}$ \\
Age & $(2.354)$ & $(1.732)$ \\
& 0.738 & $-1.845^{* * *}$ \\
Wealth index & $(0.811)$ & $(0.596)$ \\
& $13.41 * * *$ & $2.918 * * *$ \\
Number of meals per day & $(0.749)$ & $(0.563)$ \\
Distance to school & $14.37 * * *$ & $6.242^{* * *}$ \\
Family size & $(2.479)$ & $(1.821)$ \\
Constant & $-0.128 * *$ & -0.0481 \\
Prior Test Score & $(0.0587)$ & $(0.0431)$ \\
& $-3.362^{* * *}$ & $-1.229 * * *$ \\
Observations & $(0.393)$ & $(0.289)$ \\
R-squared & $505.6 * * *$ & $180.9 * * *$ \\
& $(13.87)$ & $(10.88)$ \\
& & 8,251 \\
& 8,251 & 0.502 \\
& 0.074 & Yes \\
\hline
\end{tabular}

t-test significance: $* * * \mathrm{p}<0.01,{ }^{*} \mathrm{p}<0.05,{ }^{*} \mathrm{p}<0.1$ 
Table 7. Key characteristics of linked school survey sample, according to four cohorts.

\begin{tabular}{lcccccc}
\hline & $\begin{array}{c}\text { Grade in } \\
\mathbf{2 0 1 2 - 1 3}\end{array}$ & $\begin{array}{c}\text { Grade in } \\
\mathbf{2 0 1 6 - 1 7}\end{array}$ & $\begin{array}{c}\text { \% of } \\
\text { linked } \\
\text { sample }\end{array}$ & $\begin{array}{c}\text { Age in } \\
\mathbf{2 0 1 2 - 1 3}\end{array}$ & \% FGL & $\begin{array}{c}\text { Wealth } \\
\text { index }\end{array}$ \\
\hline Cohort 1 & 4 & 8 & 65.6 & 10.7 & 9.7 & 0.12 \\
Cohort 2 & 4 & 7 & 13.3 & 11.0 & 12.2 & -0.1 \\
Cohort 3 & 5 & 8 & 15.8 & 11.8 & 11.2 & 0.05 \\
Cohort 4 & 5 & 7 & 5.3 & 12.1 & 16.0 & -0.39 \\
Total & - & - & 100 & 11.0 & 10.6 & 0.05 \\
\hline
\end{tabular}


Table 8. Test scores in mathematics by FGL Status

\begin{tabular}{|l|l|l|l|l|l|l|}
\hline & $\begin{array}{l}\text { Start of } \\
\text { Grade 4 }\end{array}$ & $\begin{array}{l}\text { End of } \\
\text { Grade 4 }\end{array}$ & Progress & $\begin{array}{l}\text { Start of } \\
\text { Grade } \\
\mathbf{8}\end{array}$ & $\begin{array}{l}\text { End of } \\
\text { Grade } \\
\mathbf{8}\end{array}$ & Progress \\
\hline FGL & 466 & 494 & 21 & 495 & 537 & 34 \\
\hline Not FGL & 499 & 535 & 31 & 541 & 580 & 31 \\
\hline Sig. & $* * *$ & $* * *$ & - & $* * *$ & $* * *$ & - \\
\hline \multicolumn{7}{|c|}{ t-test significance $* * * \mathrm{p}<0.01, * * \mathrm{p}<0.05, * \mathrm{p}<0.1$}
\end{tabular}


Figure 1. Proportion of first-generation learners by Young Lives site, Grades 7 and 8

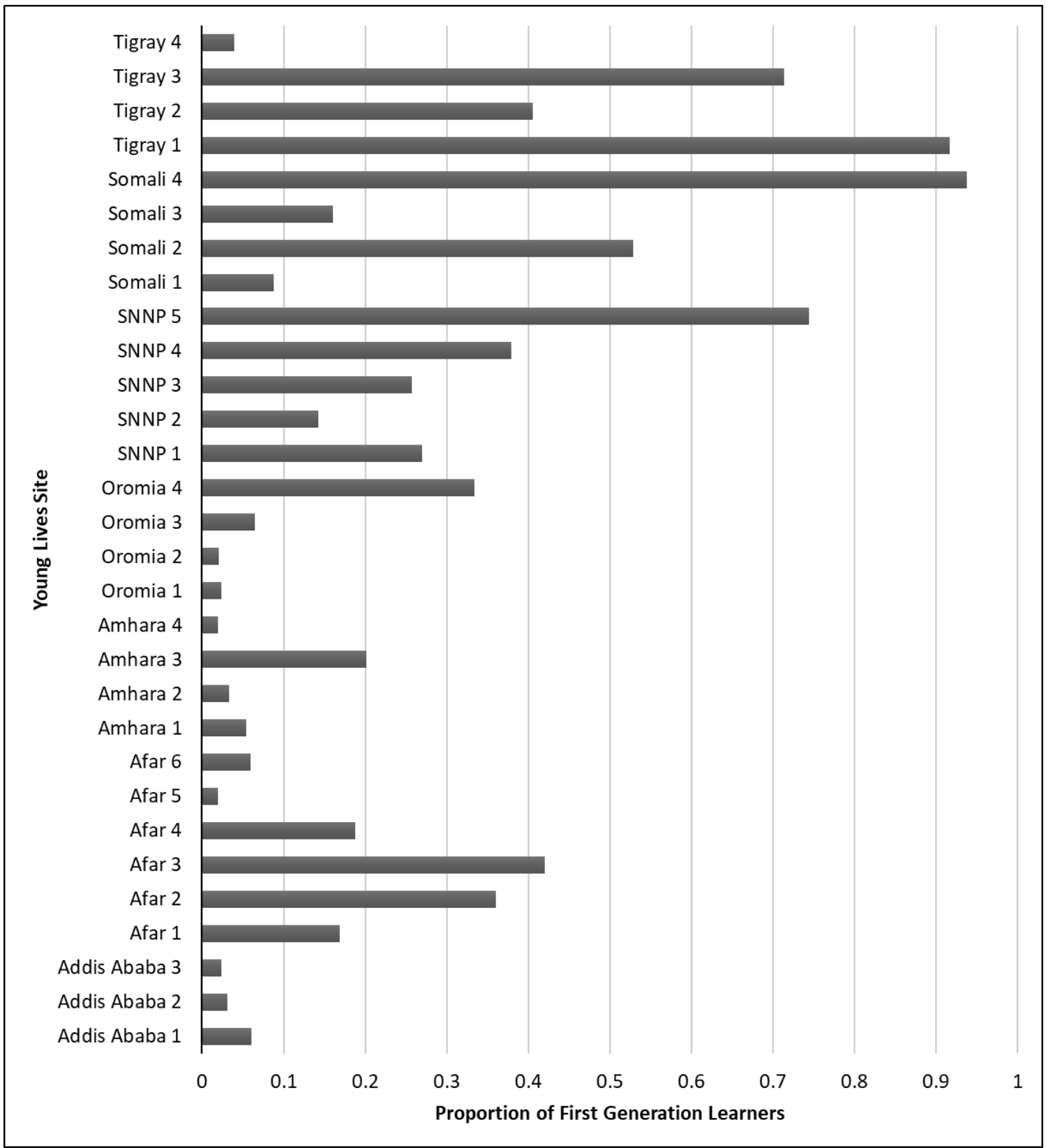

SNNP: Southern Nations and People's Region

Source: Young Lives 